\title{
Risk stratification for COPD diagnosis through an active search strategy in primary care
}

\author{
This article was published in the following Dove Press journal: \\ International Journal of COPD \\ I March 2016 \\ Number of times this article has been viewed
}

\author{
Pedro J Marcos' \\ Rosa Malo de Molina ${ }^{2}$ \\ Ricard Casamor ${ }^{3}$ \\ 'Servicio de Neumología, Instituto de \\ investigación Biomédica de A Coruña \\ (INIBIC), Complejo Hospitalario \\ Universitario de A Coruña (CHUAC), \\ Sergas Universidade da Coruña \\ (UDC), A Coruña, ${ }^{2}$ Servicio de \\ Neumología, Hospital Universitario \\ Puerta de Hierro, Majadahonda, \\ Madrid, ${ }^{3}$ Medical Department, \\ Novartis Farmacéutica SA, Barcelona, \\ Spain
}

Correspondence: Rosa Malo de Molina Servicio de Neumología, Hospital Universitario Puerta de Hierro, Calle Manuel de Falla, I, 28222 Majadahonda, Madrid, Spain

Email rmm02004@yahoo.es
Background: The aim of this study was to identify the percentage of undiagnosed patients with COPD through the implementation of an active search strategy in a selected subject population. Methods: An observational, cross-sectional, multicenter study was conducted in a primary care setting in Spain. General practitioners gave their diagnostic impression of COPD (yes/no) on the basis of clinical criteria of subjects with respiratory symptoms and tobacco exposure. Subsequently, post-bronchodilator spirometry and quality-of-life tests were performed. Multivariate logistic regression techniques using receiver operating characteristic (ROC) curves were used to identify the combination of variables that best discriminates COPD.

Results: A total of 2,758 patients were screened at 368 primary care centers, of which 1,725 patients were included in the study. Seven hundred and ninety-three patients $(46 \%)$ were diagnosed with COPD. Clinical judgment resulted in suspected COPD in 1,393 (81\%) of the subjects. The best variables to discriminate COPD were a history of lower respiratory tract infections, cough, and dyspnea. This combination identified COPD with a $\mathrm{ROC}_{\mathrm{AUC}}$ of 0.61 denoting a poor discriminative ability.

Conclusion: Employing an active search strategy leads to a new COPD diagnosis in almost half of the subjects. Screening of COPD with post-bronchodilator spirometry should be considered mandatory for any high-risk subject visiting the general practitioner clinic for any reason.

Keywords: COPD, post-bronchodilator spirometry, primary care, screening

\section{Background}

The physiological basis of COPD is an incompletely reversible airflow obstruction caused by active smoking, which is universally accepted as the most important risk factor for COPD. ${ }^{1,2}$ COPD is associated with frequent hospitalization requirements, ${ }^{3}$ high morbidity and mortality, ${ }^{3,4}$ a significant impairment in quality of life (QoL), ${ }^{5}$ and high costs. ${ }^{6,7}$ Furthermore, the relevance of severe COPD for health status is higher than that of cardiovascular diseases or diabetes. ${ }^{8}$ A number of studies have shown that COPD remains underdiagnosed ${ }^{9-13}$ likely resulting in faster disease progression and increased risk of exacerbations.

According to the EPI-SCAN study, 10\% of the Spanish population suffers from COPD,${ }^{14}$ and despite a recent trend of a reduction in the number of cases, ${ }^{15}$ EPI-SCAN study showed that there was a 73\% underdiagnosis of COPD in Spain. ${ }^{15}$ Epidemiological studies show that mortality is increasing and estimate that by 2020 COPD will be the third leading cause of mortality worldwide. ${ }^{16,17}$ Together, these negative effects on health status lead to undiagnosed COPD being a major problem for health care systems. ${ }^{14,18}$

General practitioners (GPs) are the health care professionals (HCPs) most closely linked to patients who have either respiratory symptoms or other acute health

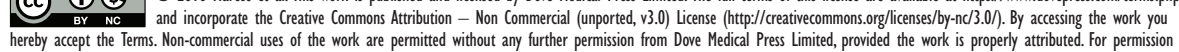
for commercial use of this work, please see paragraphs 4.2 and 5 of our Terms (https://www.dovepress.com/terms.php). 
concerns. ${ }^{13}$ Moreover, current or former smokers frequently make appointments with their GPs in relation to other comorbid conditions. Therefore, GPs are the most suitable HCPs for undertaking an active search for undiagnosed patients with COPD. However, despite GPs being perfectly positioned to detect COPD early, few studies have tried to determine whether developing an active intervention protocol to identify at-risk subjects has an impact on the diagnosis strategy.

Together, these issues prompted the design of this study. We hypothesized that an active search program in a high-risk population, through the intervention of GPs, is an effective method to detect undiagnosed cases of COPD. The aim of this study was to identify the percentage of undiagnosed patients with COPD through the implementation of an active search strategy in a selected subject population. Secondary outcomes were to identify differences in the clinical and demographic characteristics between patients who received a diagnosis of COPD and those who did not and to ascertain whether a model based on a set of clinical and medical history data may be useful for predicting the risk of being diagnosed with COPD.

\section{Methods}

\section{Subjects}

An observational, cross-sectional, multicenter study was conducted in 268 primary care centers in Spain. Subjects who had an appointment with a GP for any reason, who were older than 40 years, current or former smokers of $>10$ pack-years, and with at least one respiratory symptom (defined as the presence of dyspnea, cough, chronic sputum production or wheezing in the last 6 months, or a history of respiratory infections) were selected. The exclusion criteria were prior COPD, asthma or any other chronic respiratory disease diagnosis, or an active respiratory pharmacological treatment. Patients who were unable to perform a postbronchodilator spirometry (PBDS) test were excluded. If the patient fulfilled the study criteria, the GP was asked whether, to his/her judgment, the patient could suffer from COPD (yes/no) based on clinical and demographic criteria, followed by a clinical confirmation/rejection of COPD using a PBDS test. A COPD diagnosis was confirmed according to the guidelines of the Global Initiative for Chronic Obstructive Lung Disease (GOLD). ${ }^{19}$ A patient was considered to have COPD if a PBDS test yielded a forced expiratory volume in 1 second/forced vital capacity ratio $<0.7$. The PBDS test was performed by their GP, or a nurse with prior pulmonary function test experience, using the same American Thoracic Society/European Respiratory Society standard-certified spirometer used in the HCP's routine practice.
The study was conducted in accordance with the Declaration of Helsinki. The Institutional Ethics Committee of Galicia approved the study protocol with the number 2012/104, and the subjects provided written informed consent prior to participation.

\section{Outcomes}

The main outcome was the percentage of patients who received a correct diagnosis of COPD by following an active search strategy. In patients with COPD, the demographic and clinical characteristics were compared between patients graded I-IV using the GOLD criteria for severity of obstruction. Additional endpoints were QoL and dyspnea intensity. QoL was assessed using the validated COPD assessment test, scoring patient QoL between 0 and 40 (best-to-worst QoL scale). ${ }^{20}$ Dyspnea intensity was measured using the modified Medical Research Council scale that has five possible scores (from 0 to 4 ) with an increasing score representing increased disability. ${ }^{21}$

\section{Statistical analysis}

Results are presented as mean \pm standard deviation (SD) for quantitative variables or as absolute values and frequency for qualitative variables. Inferential statistics were performed using the chi-square test to determine associations between categorical variables and the Student's $t$-test to compare the means of quantitative variables, and a $P$-value $<0.05$ was considered significant. Logistic regression analysis was performed in order to ascertain which clinical and demographic variables were associated with the dependent variable: COPD diagnosis. Receiver operating characteristic (ROC) curves were constructed, and its area under the curve (AUC) was calculated in order to select the model with the best accuracy. All analyses were performed using SAS Version 9.2.

\section{Results}

A total of 2,758 subjects from 268 primary care centers in Spain were screened, 1,725 of which were evaluable and thus included in the study. The demographic results are shown in Table 1, and the patient's disposition is shown in Figure 1. Mean post-bronchodilator forced expiratory volume in 1 second and forced vital capacity were 2,238 $\mathrm{mL}$ and $3,135 \mathrm{~mL}$, respectively. More than half of the patients (54\%) had a history of lower respiratory tract infection. Seventytwo percent of the patients had at least one comorbid disease (with the most frequent comorbidities being hypertension and diabetes). 
Table I Demographic and clinical characteristics of the whole population by COPD diagnosis

\begin{tabular}{|c|c|c|c|c|}
\hline Characteristic & Total $\mathbf{N}=1,725$ & COPD $\mathbf{N}=793$ & Non-COPD N=932 & $P$-value \\
\hline Sex (male), n (\%) & I,23I (7I.4) & $587(74.1)$ & $644(69.1)$ & 0.0554 \\
\hline Age (years), mean (SD) & $60.1(10.2)$ & $61.3(10.0)$ & $59.1(10.3)$ & $<0.0001$ \\
\hline BMI $\left(\mathrm{kg} / \mathrm{m}^{2}\right)$, mean $(\mathrm{SD})$ & $27.5(4.1)$ & $27.4(4.1)$ & $27.6(4.2)$ & 0.66 \\
\hline \multicolumn{5}{|l|}{ Smoking habit, n (\%) } \\
\hline Current smoker & $1,003(58.1)$ & $463(58.4)$ & $540(57.9)$ & 0.78 \\
\hline Former smoker & $722(4 I .9)$ & $330(4 I .6)$ & $392(42.0)$ & \\
\hline Total smoking time (years), mean (SD) & $33.1(10.4)$ & $34.0(10.4)$ & $32.3(10.4)$ & 0.0011 \\
\hline History of low respiratory infections, $n(\%)$ & $94 \mid(54.6)$ & $489(61.7)$ & $452(48.5)$ & $<0.0001$ \\
\hline Comorbidities (yes), n (\%) & $1,240(71.9)$ & $609(76.8)$ & $631(67.7)$ & $<0.0001$ \\
\hline \multicolumn{5}{|l|}{ Symptoms, n (\%) } \\
\hline Chronic cough & $1,293(75.0)$ & $639(80.6)$ & $654(70.2)$ & $<0.000$ I \\
\hline Chronic sputum & $1,080(62.6)$ & $525(66.2)$ & $555(59.6)$ & 0.0064 \\
\hline \multicolumn{5}{|l|}{ Complications in the last year, $\mathrm{n}(\%)$} \\
\hline Acute bronchitis & $969(56.2)$ & $486(6 \mid .3)$ & $483(51.8)$ & 0.0001 \\
\hline Acute bronchitis + hospitalization & $211(12.2)$ & 118 (14.9) & $93(10.0)$ & 0.0037 \\
\hline
\end{tabular}

Abbreviations: BMI, body mass index; SD, standard deviation.

\section{COPD diagnosis}

Regarding the main study objective, 793 out of 1,725 subjects $(46 \%)$ were diagnosed with COPD by PBDS. According to the GP's clinical judgment, 1,393 (81\%) patients were presumed to have COPD. The sensibility, specificity, positive predicted value, and negative predicted value for the GP's clinical judgment for diagnosing COPD were $0.92,0.27,0.52$, and 0.80 , respectively. In total, COPD was correctly diagnosed by clinical judgment in $92 \%$ of patients who were PBDS confirmed (Table 2). However, $72 \%$ of patients who were not PBDS confirmed to have COPD received a false-positive diagnosis by clinical judgment (overdiagnosis), whereas $8 \%$ of patients received a false-negative diagnosis (underdiagnosis). As the stage of COPD increased, the accuracy of clinical criteria improved (data not shown).

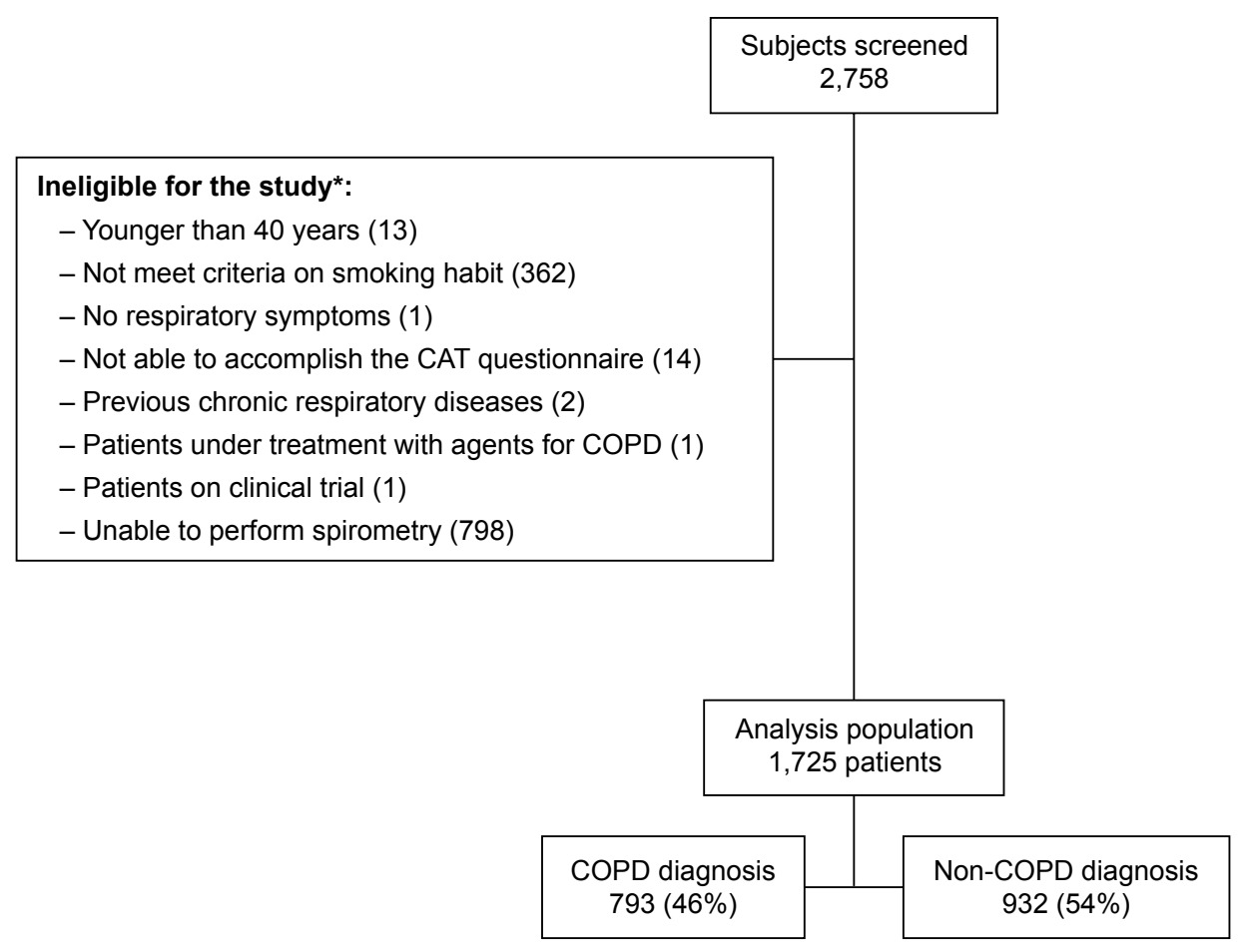

Figure I Patient disposition.

Note: *Some patients had more than one case of ineligibility.

Abbreviation: CAT, COPD Assessment Test. 
Table 2 Lung function and quality of life of the whole population by COPD diagnosis

\begin{tabular}{|c|c|c|c|c|}
\hline Variable & Total $\mathbf{N}=1,725$ & COPD $\mathrm{N}=793$ & Non-COPD N=932 & $P$-value \\
\hline 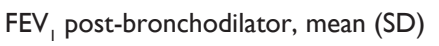 & $2,238.1(943.1)$ & & & \\
\hline$\% \mathrm{FEV}_{1}$ (of reference), mean (SD) & $73.6(21.1)$ & & & \\
\hline \multicolumn{5}{|l|}{ Clinical judgment, $n(\%)$} \\
\hline Patient has COPD & I,393 (80.8) & $725(91.4)$ & $668(71.7)$ & $<0.0001$ \\
\hline Patient does not have COPD & $311(18.0)$ & $61(7.7)$ & $250(26.8)$ & \\
\hline \multicolumn{5}{|l|}{ Dyspnea by mMRC scale, n (\%) } \\
\hline 0 & $293(17.0)$ & $84(10.6)$ & $209(22.4)$ & $<0.000$ I \\
\hline 1 & $846(49.0)$ & $390(49.2)$ & $456(48.9)$ & \\
\hline 2 & $385(22.3)$ & $227(28.6)$ & I58 (I7.0) & \\
\hline 3 & $105(6.1)$ & $63(7.9)$ & $42(4.5)$ & \\
\hline 4 & $10(0.6)$ & $4(0.5)$ & $6(0.6)$ & \\
\hline \multicolumn{5}{|l|}{ Severity of obstruction, n (\%) } \\
\hline GOLD I: FEV,$\geq 80 \%$ & & $147(18.5)$ & & \\
\hline GOLD $2: 50 \% \leq \mathrm{FEV},<80 \%$ & & $472(59.5)$ & & \\
\hline GOLD $3: 30 \% \leq \mathrm{FEV}_{1}<50 \%$ & & $140(17.7)$ & & \\
\hline GOLD 4: $\mathrm{FEV},<30 \%$ & & $34(4.3)$ & & \\
\hline CAT score, mean (SD) & $16.3(7.7)$ & I8.| (7.5) & $14.8(7.5)$ & $<0.0001$ \\
\hline
\end{tabular}

Abbreviations: $\mathrm{FEV}_{1}$, forced expiratory volume in I second; SD, standard deviation; mMRC, modified Medical Research Council; GOLD, Global Initiative for Chronic Obstructive Lung Disease; CAT, COPD Assessment Test.

A comparison between the group of patients with confirmed COPD and the group of patients without COPD showed that patients with COPD had a higher frequency of lower respiratory tract infections (62\% vs 49\%,P<0.0001); comorbidities (77\% vs 68\%, $P<0.0001)$, chronic cough $(81 \%$ vs $70 \%, P<0.0001)$, chronic sputum production $(66 \%$ vs $60 \%, P=0.0064)$, history of acute bronchitis ( $61 \%$ vs $52 \%$, $P=0.0001)$, and acute bronchitis leading to hospitalization (15\% vs $10 \%, P=0.0037$ ).

The QoL and degree of dyspnea are shown in Table 2. Among patients with COPD, the association between COPD stage (I, II, III, IV) and the demographic and clinical characteristics was investigated. The results showed that as the level of airflow limitation increased, patients were older $(P<0.0001)$, had smoked more pack-years $(P=0.0002)$, had an increased COPD diagnosis accuracy via clinical judgment $(P<0.0001)$, and had more chronic cough $(P=0.0001)$, more chronic sputum production $(P=0.0096)$, more exacerbations $(P=0.0002)$, more hospitalizations due to exacerbations $(P<0.0001)$, a poorer QoL $(P<0.0001)$, and a more severe dyspnea score $(P<0.0001)$.

\section{Predictors of COPD diagnosis}

A logistic regression analysis and ROC curves were performed, including three (previous lower respiratory infection, dyspnea, chronic cough) and four variables (previous lower respiratory infection, dyspnea, chronic cough, and comorbidities) in the models to assess which was the best model to predict the risk of having a diagnosis of COPD.
Results showed that the set of three criteria (prior lower respiratory tract infection, dyspnea, and chronic cough) were in the model as independent predictors of the risk of COPD. This model was shown to have the best AUC (0.61) in the ROC curve. These results are shown in Table 3 and Figure 2.

\section{Discussion}

This study shows that an active search strategy for patients with COPD yields a remarkable result when performed in a selected population that is considered to be high risk by demographic and clinical criteria. Almost half of the subjects screened in this Spanish population received a diagnosis of COPD on the basis of the 2011 GOLD criteria. This finding should be highlighted and used to promote

Table 3 Logistic regression analysis (predictive model)

\begin{tabular}{|c|c|c|c|}
\hline Model & $P$-value & OR & $95 \% \mathrm{Cl}$ \\
\hline $\begin{array}{l}\text { Previous lower respiratory } \\
\text { tract infections (yes/no) }\end{array}$ & 0.0011 & 1.40 & $|| 4-.|.7|$ \\
\hline Dyspnea (yes/no) & $<0.000 \mathrm{I}$ & 2.29 & $1.77-2.96$ \\
\hline Chronic cough (yes/no) & 0.0046 & $1.4 \mathrm{I}$ & $1.11-1.79$ \\
\hline$A U C=0.6121$ & & & \\
\hline Sensitivity $=48.4 \mathrm{I}$ & & & \\
\hline Specificity $=66.04$ & & & \\
\hline False-positive rate $=44.62$ & & & \\
\hline False-negative rate $=40.48$ & & & \\
\hline Positive predictive value $=0.55$ & & & \\
\hline Negative predictive value $=0.60$ & & & \\
\hline
\end{tabular}

Abbreviations: $\mathrm{OR}$, odds ratio; $\mathrm{Cl}$, confidence interval; $\mathrm{AUC}$, area under the curve. 


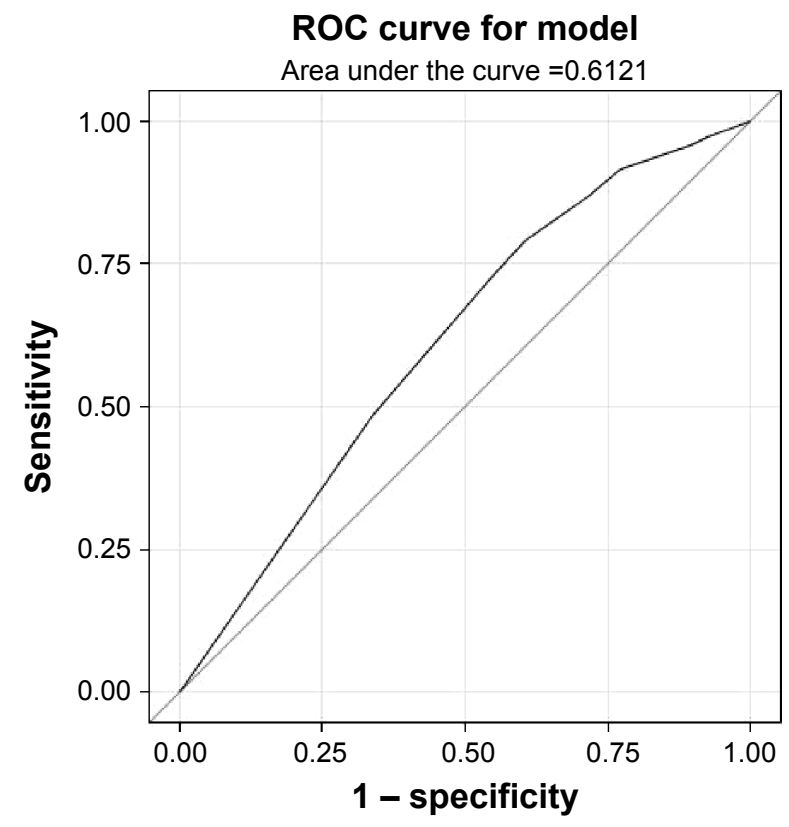

Figure $\mathbf{2}$ ROC curve of the best model (model with respiratory infections, dyspnea, and chronic cough).

Abbreviation: ROC, receiver operating characteristic.

the necessity of searching for symptoms in patients with a history of tobacco consumption in order to achieve earlier COPD detection.

The selection of the patients was a key issue, and the results indicate that a strategy based on the active screening of high-risk patients should be considered mandatory. Other studies carried out on non-preselected Spanish populations found fewer patients with a final COPD diagnosis: $20 \%$ of the subjects in the BOLD study ${ }^{22}$ and $10 \%$ in the EPI-SCAN. ${ }^{15}$ Two studies based on similar active search strategies, performed in Belgium and the Netherlands, found that $47 \%$ and $41 \%$ of subjects received a diagnosis of COPD, respectively. ${ }^{13,23}$ Thus, in general, the epidemiological prevalence of COPD in the overall population (unselected) is $\sim 10 \%,{ }^{17,24,25}$ but active search studies in a high-risk patient cohort attending a GP clinic may have higher rates of diagnosis. ${ }^{22}$ The results presented here are comparable with a number of studies that showed that COPD prevalence is higher, between $25 \%$ and $50 \%$, in a highly select population ${ }^{1,16,23,26-31}$ than in the overall unselected population. When an active search is performed in a high-risk group of patients, almost half of the patients receive a diagnosis of COPD. This high percentage should be properly valued as it may allow an early treatment for these patients and a correct diagnosis in case of an exacerbation. This procedure may minimize exacerbations, hospitalizations, and respiratory complaints and improve overall patient QoL.
This study shows that the clinical judgment of the GPs before the PBDS test predominantly resulted in overdiagnosis. However, cough, expectoration, and wheezing remain very useful in the follow-up of patients with a known diagnosis of COPD. Furthermore, the clinical judgment alone showed to have a low positive predictive value since almost three out of four of the subjects who were considered as having COPD by the GP were not confirmed by PBDS, which highlights the importance of spirometry testing for COPD confirmation.

The results of the discriminative ability of clinical methods other than PBDS agree with previous studies that have also shown that clinical data have a low predictive capability for COPD screening. ${ }^{23} \mathrm{~W}$ ithin this group, a history of lower respiratory tract infections was the best clinical item in order to discriminate between patients with and without COPD. ${ }^{32,33}$ This important finding highlights the need to investigate a possible COPD diagnosis in any patient with a history of lower respiratory tract infection.

Although cough and chronic sputum production were the cornerstone for the outdated clinical definition of COPD, unlike previous studies, ${ }^{30}$ no predictive capability was observed for such factors in our population.

The predictive models based on clinical and demographic characteristics presented in this study are poor. The most accurate predictive model included a combination of chronic cough with the presence of dyspnea and previous respiratory infections. Indeed, this model showed that the three risk factors were independently predictive of the risk of having COPD. However, this model yielded a $\mathrm{ROC}_{\mathrm{AUC}}$ of 0.61 , denoting a poor predictive ability. This result is in full agreement with the aforementioned Dutch study by Kotz et al, ${ }^{23}$ whose questionnaire also had a low $\mathrm{ROC}_{\mathrm{AUC}}$ and was also concluded to not improve the identification of undiagnosed COPD cases. A substudy of the BOLD study ${ }^{31}$ that focused on the utility of peak flow spirometry in the screening of undiagnosed patients with COPD also demonstrated that the results of screening with clinical criteria alone were poor. PBDS is the gold standard test to diagnose COPD for its simplicity and lower economic cost. ${ }^{31}$ Therefore, our results confirm the crucial role that spirometry plays in the diagnosis of COPD when highrisk populations are screened with active search strategies. Moreover, these strategies are cost-effective, ${ }^{31}$ making them even more attractive to health care system managers.

We would also like to highlight the importance of undiagnosis at the individual level since it has been described that undiagnosed patients represent the $34 \%$ of all patients hospitalized for the first time because of an exacerbation of COPD. ${ }^{34}$ 
This study has some limitations. First, the clinical judgment of the GPs was requested via a somewhat imprecise and general question; however, the intent of this study was to simulate real-life settings that would include the GP's personal opinion. Second, a selection bias may be observed when the patient is asked the subjective question of whether they are suffering from a respiratory symptom by HCPs motivated by participation in an investigational study. Third, all the data were analyzed together so we cannot discard a "center effect" which could bias the results. And finally, it is very important to ascertain the feasibility of the system in a real-world setting. Indeed, the performance of a systematic screen with PBDS, albeit in a selected high-risk population, may be problematic in health care systems with limited economic and human resources that, more importantly, may end up with a very high number of new patients with COPD.

\section{Conclusion}

In conclusion, employing an active search strategy leads to a new COPD diagnosis in almost half of the patients. Both the accuracy of clinical judgment in the diagnosis of COPD and the predictive power of a model based on clinical criteria are poor. Screening COPD with PBDS should be considered mandatory for any high-risk patient attending a GP clinic for any reason.

\section{Acknowledgments}

The authors would like to thank all the primary care physicians who participated in the study. The authors also wish to thank Eva Mateu from TFS who provided medical writing services on behalf of Novartis Farmacéutica SA, Barcelona, Spain. Financial support for the study was provided by Novartis Farmacéutica SA, Barcelona, Spain.

\section{Author contributions}

PJM, RMM, and RC designed and supervised the overall study. PJM, RMM, and RC participated in the writing of the manuscript, provided important intellectual content, and gave their final approval of the version submitted for publication. All authors contributed toward data analysis, drafting and critically revising the paper and agree to be accountable for all aspects of the work.

\section{Disclosure}

PJM and RMM declare that they have no competing interests. $\mathrm{RC}$ is an employee of Novartis. The authors report no other conflicts of interest in this work.

\section{References}

1. Zieliñski J, Bednarek M; Know the Age of Your Lung Study Group. Early detection of COPD in a high-risk population using spirometric screening. Chest. 2001;119(3):731-736.

2. Hagstad S, Bjerg A, Ekerljung L, et al. Passive smoking exposure is associated with increased Risk of COPD in never smokers. Chest. 2014; 145(6): 1298-1304.

3. Gudmundsson G, Gislason T, Janson C, et al. Depression, anxiety and health status after hospitalisation for COPD: a multicentre study in the Nordic countries. Respir Med. 2006;100(1):87-93.

4. Almagro P, Calbo E, Ochoa de Echagüen A, et al. Mortality after hospitalization for COPD. Chest. 2002;121(5):1441-1448.

5. Almagro P, Castro A. Helping COPD patients change health behavior in order to improve their quality of life. Int J Chron Obstruct Pulmon Dis. 2013;8:335-345.

6. Loddenkemper R, Gibson GJ, Sibille Y. The burden of lung disease in Europe: why a European White Book on lung disease? Eur Respir J. 2003;22(6):869.

7. Nielsen R, Johannessen A, Benediktsdottir B, et al. Present and future costs of COPD in Iceland and Norway: results from the BOLD study. Eur Respir J. 2009;34(4):850-857.

8. Janson C, Marks G, Buist S, et al. The impact of COPD on health status: findings from the BOLD study. Eur Respir J. 2013;42(6):1472-1483.

9. Bednarek M, Maciejewski J, Wozniak M, Kuca P, Zielinski J. Prevalence, severity and underdiagnosis of COPD in the primary care setting. Thorax. 2008;63(5):402-407.

10. Albers M, Schermer T, Molema J, et al. Do family physicians' records fit guideline diagnosed COPD? Fam Pract. 2009;26(2):81-87.

11. Broekhuizen BDL, Sachs APE, Hoes AW, et al. Undetected chronic obstructive pulmonary disease and asthma in people over 50 years with persistent cough. Br J Gen Pract. 2010;60(576):489-494.

12. Decramer M, Miravitlles M, Price D, et al. New horizons in early stage COPD - improving knowledge, detection and treatment. Respir Med. 2011;105(11):1576-1587.

13. Vandevoorde J, Verbanck S, Gijssels L, et al. Early detection of COPD: a case finding study in general practice. Respir Med. 2007;101(3): 525-530.

14. Miravitlles M, Soriano JB, García-Río F, et al. Prevalence of COPD in Spain: impact of undiagnosed COPD on quality of life and daily life activities. Thorax. 2009;64(10):863-868.

15. Soriano JB, Ancochea J, Miravitlles M, et al. Recent trends in COPD prevalence in Spain: a repeated cross-sectional survey 1997-2007. Eur Respir J. 2010;36(4):758-765.

16. Murray CJ, Lopez AD. Mortality by cause for eight regions of the world: Global Burden of Disease Study. Lancet. 1997;349(9061): 1269-1276.

17. Raherison C, Girodet P-O. Epidemiology of COPD. Eur Respir Rev. 2009;18(114):213-221.

18. Pauwels R. COPD: the scope of the problem in Europe. Chest. 2000; 117(5 suppl 2):332S-335S.

19. Global Strategy for the Diagnosis, Management and Prevention of COPD [homepage on the Internet]. Global Initiative for Chronic Obstructive Lung Disease (GOLD) 2015. Available from: http://www. goldcopd.org/. Accessed January 12, 2016.

20. Jones PW, Harding G, Berry P, Wiklund I, Chen W-H, Kline Leidy N. Development and first validation of the COPD Assessment Test. Eur Respir J. 2009;34(3):648-654.

21. Bestall JC, Paul EA, Garrod R, Garnham R, Jones PW, Wedzicha JA. Usefulness of the Medical Research Council (MRC) dyspnoea scale as a measure of disability in patients with chronic obstructive pulmonary disease. Thorax. 1999;54(7):581-586.

22. Buist AS, McBurnie MA, Vollmer WM, et al; BOLD Collaborative Research Group. International variation in the prevalence of COPD (the BOLD Study): a population-based prevalence study. Lancet. 2007; 370(9589):741-750.

23. Kotz D, Nelemans P, van Schayck CP, Wesseling GJ. External validation of a COPD diagnostic questionnaire. Eur Respir J. 2008;31(2):298-303. 
24. Halbert RJ, Natoli JL, Gano A, Badamgarav E, Buist AS, Mannino DM. Global burden of COPD: systematic review and meta-analysis. Eur Respir J. 2006;28(3):523-532.

25. Halbert RJ, Isonaka S, George $\mathrm{D}$, Iqbal A. Interpreting COPD prevalence estimates: what is the true burden of disease? Chest. 2003; 123(5):1684-1692.

26. Buffels J, Degryse J, Heyrman J, Decramer M; DIDASCO Study. Office spirometry significantly improves early detection of COPD in general practice: the DIDASCO Study. Chest. 2004;125(4):1394-1399.

27. Geijer RMM, Sachs APE, Hoes AW, Salomé PL, Lammers J-WJ, Verheij TJM. Prevalence of undetected persistent airflow obstruction in male smokers 40-65 years old. Fam Pract. 2005;22(5):485-489.

28. Lundbäck B, Lindberg A, Lindström M, et al; Obstructive Lung Disease in Northern Sweden Studies. Not 15 but $50 \%$ of smokers develop COPD? - Report from the Obstructive Lung Disease in Northern Sweden Studies. Respir Med. 2003;97(2):115-122.

29. Stratelis G, Jakobsson P, Molstad S, Zetterstrom O. Early detection of COPD in primary care: screening by invitation of smokers aged 40 to 55 years. Br J Gen Pract. 2004;54(500):201-206.
30. Van Schayck CP, Loozen JMC, Wagena E, Akkermans RP, Wesseling GJ. Detecting patients at a high risk of developing chronic obstructive pulmonary disease in general practice: cross sectional case finding study. BMJ. 2002;324(7350):1370.

31. Jithoo A, Enright PL, Burney P, et al; BOLD Collaborative Research Group. Case-finding options for COPD: results from the Burden of Obstructive Lung Disease study. Eur Respir J. 2013;41(3):548-555.

32. Hooper R, Burney P, Vollmer WM, et al. Risk factors for COPD spirometrically defined from the lower limit of normal in the BOLD project. Eur Respir J. 2012;39(6):1343-1353.

33. Jones RCM, Price D, Ryan D, et al; Respiratory Effectiveness Group. Opportunities to diagnose chronic obstructive pulmonary disease in routine care in the UK: a retrospective study of a clinical cohort. Lancet Respir Med. 2014;2(4):267-276.

34. Balcells E, Gimeno-Santos E, de Batlle J, et al; PAC-COPD Study Group. Characterisation and prognosis of undiagnosed chronic obstructive pulmonary disease patients at their first hospitalisation. BMC Pulm Med. 2015;15:4.
International Journal of COPD

\section{Publish your work in this journal}

The International Journal of COPD is an international, peer-reviewed journal of therapeutics and pharmacology focusing on concise rapid reporting of clinical studies and reviews in COPD. Special focus is given to the pathophysiological processes underlying the disease, intervention programs, patient focused education, and self management protocols.

\section{Dovepress}

This journal is indexed on PubMed Central, MedLine and CAS. The manuscript management system is completely online and includes a very quick and fair peer-review system, which is all easy to use. Visit http://www.dovepress.com/testimonials.php to read real quotes from published authors.

Submit your manuscript here: http://www.dovepress.com/international-journal-of-chronic-obstructive-pulmonary-disease-journal 